\title{
Addressing Primary Care Inequities in Underserved Areas of the Philippines: A Review
}

\author{
Marianne Joy N. Naria-Maritana, MD, 1,2 Gabriel R. Borlongan, MD, MPM,1,3 \\ Ma-Ann M. Zarsuelo, RND, MSc, ${ }^{1,4}$ Ara Karizza G. Buan, RMicro, ${ }^{1,4}$ Frances Karen A. Nuestro, PTRP,1,4 \\ Janvic A. Dela Rosa, RND, ${ }^{1,4}$ Ma. Esmeralda C. Silva, MPAf, MSPPM, PhD, ${ }^{1,5}$ \\ Michael Antonio F. Mendoza, DDM, MA ${ }^{1,6}$ and Leonardo R. Estacio, MCD, MPH, PhD ${ }^{1,7}$ \\ ${ }^{1}$ University of the Philippines Manila Health Policy Development Hub \\ ${ }^{2}$ Department of Pediatrics, Philippine General Hospital, University of the Philippines Manila \\ ${ }^{3}$ Department of Health - Field Implementation and Coordination Team \\ ${ }^{4}$ Institute of Health Policy and Development Studies, National Institutes of Health, University of the Philippines Manila \\ ${ }^{5}$ College of Public Health, University of the Philippines Manila \\ ${ }^{6}$ College of Dentistry, University of the Philippines Manila \\ ${ }^{7}$ College of Arts and Sciences, University of the Philippines Manila
}

\begin{abstract}
Background. Inequities in health care exist in the Philippines due to various modifiable and non-modifiable determinants. Through the years, different interventions were undertaken by the government and various stakeholders to address these inequities in primary care. However, inequities still continue to persist. The enactment of the Universal Health Care (UHC) Act aims to ensure that every Filipino will have equitable access to comprehensive and quality health care services by strengthening primary care. As a step towards UHC, the government endeavors to guarantee equity by prioritizing assistance and support to underserved areas in the country. This paper aims to review different interventions to promote equity in the underserved areas that could aid in needs assessment.
\end{abstract}

Methods. A search through PUBMED and Google Scholar was conducted using the keywords, "inequity," "primary care" and "Philippines." The search yielded more than 10,000 articles which were further filtered to publication date, relevance to the topic, and credibility of source. A total of 58 full-text records were included in the review.

Results and Discussion. In the Philippines, inequities in primary care exist in the context of health programs, facilities, human health resources, finances, and training. These were recognized by various stakeholders, from government and private sector, and nongovernment organizations, taking actions to address inequities, applying different strategies and approaches but with a shared goal of improving primary care. On another end, social accountability must also be instilled among Filipinos to address identified social and behavioral barriers in seeking primary care. With political commitment, improvement in primary care towards health equity can be achieved.

Conclusion and Recommendation. To address inequities in primary care, there is a need to ensure adequate human resources for health, facilities, supplies such as medications, vaccination, clean water, and sources of funds. Moreover, regular conduct of training on healthcare services and delivery are needed. These will capacitate health workers and government leaders with continuous advancement in knowledge and skills, to be effective providers of primary care. Institutionalizing advocacy in equity through policies in healthcare provision would help realize the aims of the Universal Health Care Act.

Key Words: primary care, universal health care, inequity, Philippines

\section{INTRODUCTION}

Corresponding author: Marianne Joy N. Naria-Maritana, MD UP Manila Health Policy Development Hub National Institutes of Health

University of the Philippines Manila

623 Pedro Gil St., Ermita, Manila 1000, Philippines

Email: mnnariamaritana@up.edu.ph
Republic Act 11223, otherwise known as the Universal Health Care Act of 2019, aims to ensure equitable access to and availability of quality health care goods and services. The Law declared that protecting and promoting the right to health of every Filipino is a policy of the State. This 
further stems in the Philippine Constitution of 1987 where Article XIII, Section 11 states that the State shall adopt an approach to health development that is integrated and comprehensive which will aim to make necessary services for health and social needs available to all Filipinos at an affordable cost. It further states that the State shall give priority and provide care at no cost to the underprivileged such as persons with illnesses and disabilities, elderlies, children and women. ${ }^{1}$ The enactment of RA 11223 explicitly shows the commitment of the State to strengthen provision of health by having a health care delivery system that can provide each Filipino good primary care. ${ }^{2}$

Grounded by the "whole-of-society" framework with "people-oriented" approach, the Law envisions "a health care model that provides all Filipinos access to a comprehensive set of quality and cost-effective, promotive, preventive, curative, rehabilitative and palliative health services without causing financial hardships." ${ }^{2}$ Services are categorized to be delivered as individual-based or population-based; hence, approaches in service delivery and financing schemes varies.

Health services are deemed as population-based, as defined by the UHC Act, when these target population groups as recipients, and are provided by local health systems within the province or highly urbanized or independent component cities, together with their component local government units within the geographic area of coverage. Financing of population-based health services is borne from the National Government through the Department of Health, which shall support these province-wide or city-wide health systems in terms of capital investment and provision of services. At the minimum, the main provider of these health services shall be comprised of a network of primary care providers with health records of patients accessible throughout the system; operationalizing epidemiologic surveillance systems that are sensitive, accurate, and timely in providing data that will inform decision-making; and implementing programs and campaigns on health promotion that are proactive and effective. ${ }^{2}$

On the other hand, individual-based health services are distinctly defined as services accessible within a health facility or remotely, traceable to a single client, with limited effect to population groups and do not significantly address the underlying cause of illness. This is exemplified by ambulatory and inpatient care, medicines, laboratory tests, and procedures. Networks of providers of individual-based health services shall be contracted by PhilHealth, regardless of the nature of employment of these providers or ownership of facilities, as to public, private or mixed. ${ }^{2}$

The healthcare model embodied in the Law also recognizes the prioritization of the needs of the sub-population experiencing financial and geographical inaccessibility to healthcare services. This is consistent with the deployment of some health human resources (e.g., doctors, nurses, midwives, etc.), ${ }^{3}$ wherein health workers will be first deployed among Geographically Isolated and Disadvantaged Areas (GIDAs), and underserved areas. In the House Bill 6336 and Senate Bill 1618, underserved or unserved areas refer to communities that are isolated by circumstances such as inaccessibility due to distance or physical terrain, lack of transportation, being disaster-prone, and presence of crisis and/ or armed conflict. ${ }^{4,5}$

The World Health Organization (WHO) (2019), recognizes that primary health care is integral to the realization of universal health care as it aims to improve geographic and financial accessibility of services. A cohesive definition of primary health care includes: (1) providing "comprehensive, promotive, protective, preventive, curative, rehabilitative and palliative care" to meet the needs of the people in a lifetime, by prioritizing primary care and public health functions services; (2) addressing the different determinants of health systematically; and (3) empowering every individual, family, and community to advocate policies for health, to co- develop services for health and social needs and to take care of one's self and others. ${ }^{6}$ Thus, to bring quality services closer to the community and warrant responsive health system, it is also instructional to entice bottomup approach participation. Primary Health Care (PHC) is committed to social justice and equity. ${ }^{7}$

In the Philippines, Primary Health Care has evolved throughout the years. PHC approach was initially implemented in 1979 to 1981 in pilot provinces involving 98 municipalities selected based on the need, willingness of the local government units, condition of peace and order, and presence of organizations that could carry out the projects in the municipal and provincial levels. PHC was further launched to more areas from 1981 to 1990. In 1991, devolution of the health care system took place which involved transferring the role of PHC from the Department of Health (DOH) to the local government units (LGUs). ${ }^{8}$ With the current state of healthcare system, the $\mathrm{DOH}$ Secretary stated that the success of UHC in improving access to health services of the Filipinos "depends on how well coordination with LGUs would be carried out."

As primary health care is considered as the multi-sectoral approach encompassing various functions of the health system, primary care focuses more on the provision of health care services, defined by the RA 11223 as the "initial-contact, accessible, continuous, comprehensive and coordinated care that is accessible at the time of need including a range of services for all presenting conditions, and the ability to coordinate referrals to other health care providers in the care delivery system when necessary." ${ }^{2}$ With the framework of the service delivery of the Law, it institutionalizes the transformation of the model of care with primary care as the cornerstone in achieving universal health care. ${ }^{2}$ As primary care enhancement is under the auspices of the LGU, it therefore has a challenge to ensure that local officials be adequately oriented on the advocacies of $\mathrm{PHC}$ and to allocate sufficient resources such as trainings for health workers. ${ }^{8}$

Widespread efforts in improving delivery of health services have already been done in the country. However, 
disparities in the availability and accessibility of resources still exist. ${ }^{10}$ The 2017 National Demographic and Health Survey shows that there are disparities in both health outcomes and access to health services based on socioeconomic status and geographic area. ${ }^{11}$ Infrastructures and human resources for health are maldistributed across the country. They are highly concentrated in major cities especially in Metro Manila. ${ }^{10}$ A study by Hodge et al. (2016) found moderate disparities based on wealth in the use of institutional delivery in the country. ${ }^{12}$ Mortality rates among children under five years of age is $30.43 \%$ higher among those living in rural residences compared to those in urban areas. Coverage of age-appropriate vaccinations among children aged 1223 months was highest in Davao at 78\% while lowest in the Autonomous Region in Muslim Mindanao, at 9\%. These observations were also evident in other diseases and coverage of essential interventions done in the survey. ${ }^{11}$

Various determinants contribute to these inequities such as socioeconomic factors, population mobility, pockets of political instability, modifiable factors of the archipelagic geography and disaster risks, and population-related factors in terms of the demographic and epidemiologic transition. In health sector terms, these difficulties could be accounted to: (1) the private and public healthcare delivery sector; (2) skill deficits and maldistribution in human resources; (3) inadequate resource management; and (4) politicization of health. ${ }^{13}$ These disparities and inequity confirm the relevance of the government efforts to apply equity across health programs, reaching beyond the parameters of geographic, sociocultural, political, economic, and physical barriers in service delivery. ${ }^{12}$

The national government endeavors to guarantee equity by prioritizing assistance and support to GIDAs, and preferential licensing and contracting of health facilities in underserved areas. This is further supported by mandates accorded to the Philippine Health Insurance Corporation (PHIC) in developing differential payment schemes to providers that integrate service quality, efficiency and equity, and incentive schemes that reward health facilities that consider this domain of quality. ${ }^{2}$ In the regulation of health facilities, authorized bed capacity which depends on the facility level, takes into account the free provision of basic or ward accommodation. For compliance to the No Balance Billing (NBB) Policy, eligible beneficiaries (i.e. indigents, senior citizens, point of service patients, sponsored patients, domestic workers, lifetime members) are entitled to the benefits of the no co-payment policy from admission to discharge. ${ }^{14}$ The corresponding local government unit of the health facility is also engaged in ensuring that at least sixty three percent (63\%) are NBB compliant in 2016 with subsequent yearly increases until all are covered by $2022 . .^{15}$ This policy was further expanded in the Implementing Rules and Regulations of the UHC Act wherein no-copayments including professional fees, shall be charged to all PhilHealth members admitted in any basic or ward accommodations. ${ }^{16}$
This review aims to provide local evidence on inequities in primary care in the Philippines and the steps undertaken by the different stakeholders in addressing such inequities. This review could aid in determining areas of priorities such as underserved areas, for allocation of health investments.

\section{METHODS}

A search through PUBMED using the keywords "inequity" showed 3,146 results and narrowed down to 363 results when "inequity" and "primary care" were used. Switching to the best match sort order, "inequity", "primary care" and "Philippines" yielded 73 results. The results were then filtered by articles published from 2000 to 2019 and its contextual significance to the topic of interest. Google Scholar was also used to gather more articles. Using the keywords "inequity" and "primary care" yielded 170,000 results. These results were filtered by date, considering those from 2014 to 2019; keywords "health" and "Philippines" were further added yielding 9,730 results. Google Search using the search words was also utilized by the team for any articles, manuals, policy tools, and laws. In total, 58 records, full text were included in the review.

To properly frame the review of literature on inequities in primary care, two frameworks of analysis were used to provide guidance on how primary care inequities can be further addressed. First is the Health Inequalities Action Framework from the National Health Survey (NHS) Health Scotland, which serves as a guide on how the narrative is sequenced. Local literature was sought to determine the current status of delivering primary care, particularly on the components that influence the delivery of services (Figure 1). ${ }^{17}$

Discussion on the baseline status of primary care, and interventions of government and non-government actors, were thematically grouped using the lens of the Health Systems Dynamics framework developed by Van Olmen et al. (2013) as seen in Figure 2. ${ }^{18}$

This framework posits that while infrastructure, supplies, manpower, finances, and technical resources directly influence service delivery, leadership influences the effective transformation of these resources to service delivery. ${ }^{18}$

After presenting the baseline quantitative and descriptive status of primary care, previous and ongoing interventions to address these inequalities were then laid down, as grouped per sector of society facilitating these activities. From this review, based on the intrinsic challenges and external opportunities, recommendations were formulated and presented for possible adoption into policy reforms.

\section{RESULTS}

The WHO Commission on Social Determinants of Health (2008) reported that a major part of inequities in health is brought about by the different structural determinants and conditions of daily living. These constitute 


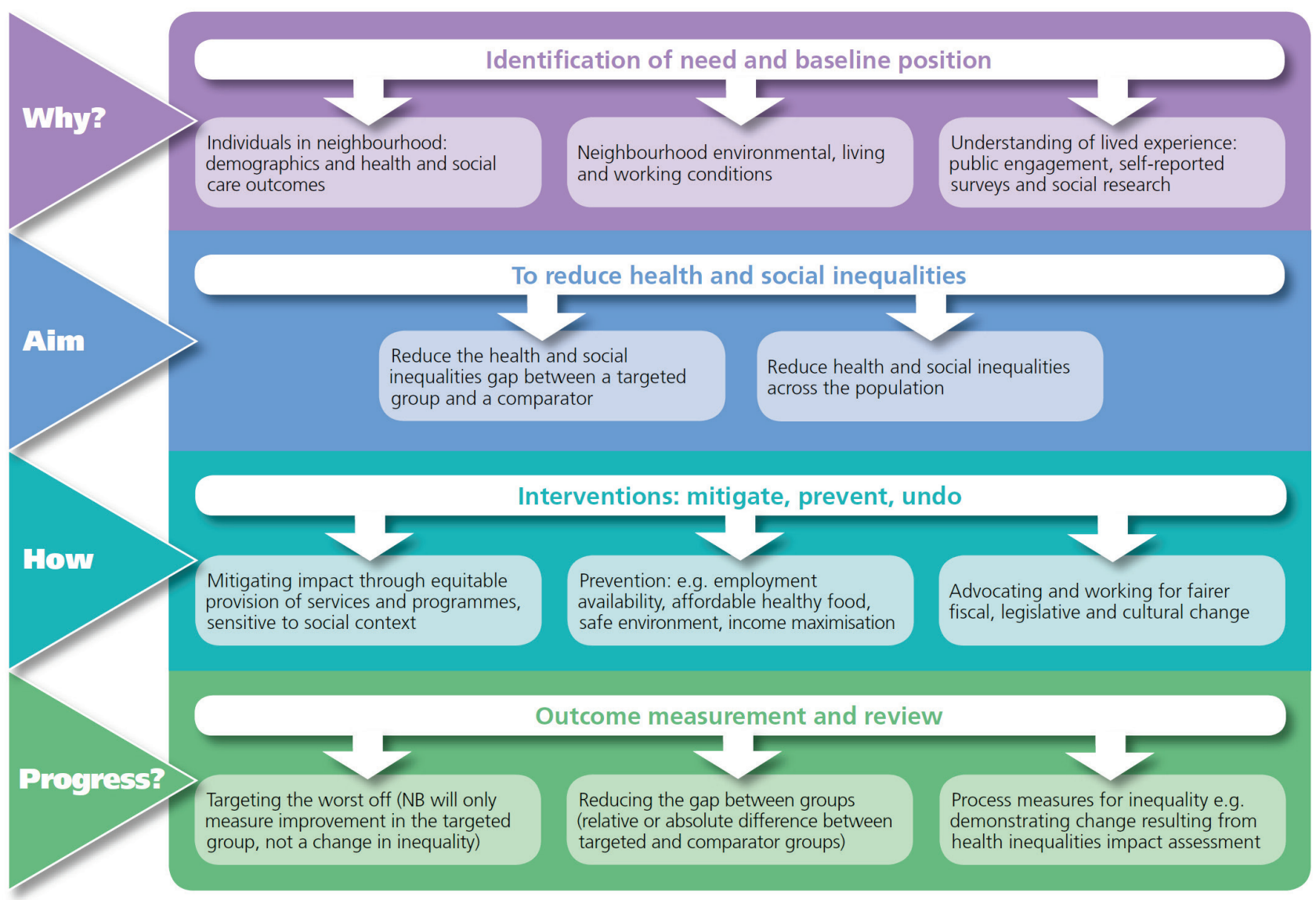

Figure 1. NHS Health Scotland Health Inequalities Action Framework. ${ }^{17}$

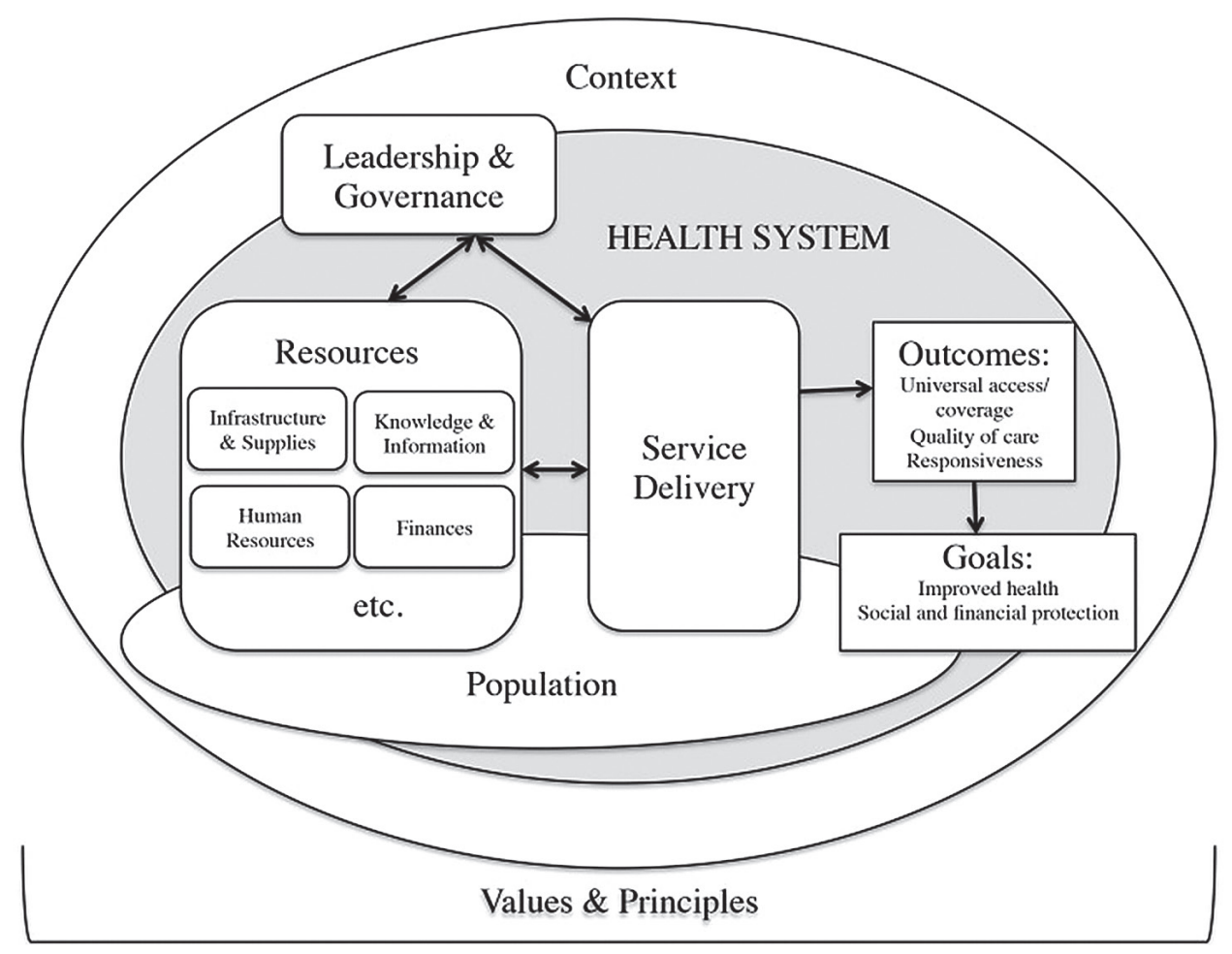

Figure 2. Health systems dynamics framework by Van Olmen, et al. (2013). ${ }^{18}$ 
the social determinants of health, delving on the demand side of service delivery. These further include uneven distribution of power, funds, commodities, and services which could result in problems of access to education, work, and healthcare. All factors interplay with the environmental setting of healthcare which are negatively affected by socialinsensitive health policies and programs, ill economic performance, and politicized governance. ${ }^{19}$ An example is the case study conducted in India wherein more resources were provided to tertiary hospitals due to the financial demands of its complex and diagnostic procedures. This resulted in inadequate funds for primary care services. ${ }^{20}$

Inequities significantly affect people's welfare, health, and development over the life course, specifically of children. ${ }^{21}$ The poor and marginalized segments of the population are challenged with the different barriers to healthcare such as:

1. Accessibility: physical access to services is made difficult in remote rural places due to limited means of transportation. In effect, there is less chance to be recipients of outreach services and contact with healthcare professionals.

2. Affordability: out-of-pocket expenditures push the poor and the marginalized to defer availing of health services.

3. Acceptability: health services that are not in congruence with the community's culture and religion may not be availed of.

4. Quality and Continuity of Care: improved health outcomes are attainable with continuity of care, and compliance of delivered services with prescribed standards, but is usually not feasible among the poor due to several resource constraints..$^{21,22}$

\section{Inequities in Primary Care in the Philippines}

In the Philippines, mortality rates have been decreasing, with neonatal mortality rate of 12.5 per 1,000 live births, the under-five mortality rate of 28 , and a maternal mortality ratio per 100,000 live births of $114 .{ }^{23}$ However, there are still vulnerable subpopulations that have not received benefits of these improvements and a fragmented health system still exists. ${ }^{23}$ The WHO reported that in 2019, 6.4 million Filipinos spend more than ten percent of their income on health care which posed catastrophic financial risk to individuals and families, further contributing to an intergenerational cycle of poverty. ${ }^{7}$

In determining the causal pathways of disease patterns and distribution, approach in analyzing evidence must be holistic. Blas et al. (2008) underscored that the biomedical approach excludes the sphere of macro-policy determinants such as social, political, and economic. ${ }^{24}$ Much has been known that social determinants affect health inequities as poor health is systematically linked with social disadvantage and marginalization. ${ }^{24}$ This further extends to economic and environmental settings. Hence, in implementing universal health intervention, it must be noted that determinants of improved health (e.g., better nutrition, health utilization, sanitation, etc.) and determinants of health inequities may not belong to the same sphere. In improving the overall health at the population level, there are differential effects between sub-groups, attributed to the catching up effect, with the marginalized and disadvantaged at the bottom. Given that various sub-population groups respond to interventions differently, the policy implications of the social structure must be considered.

In the Philippines, a study conducted by Hodge et al. (2016) on the utilization of health services, specifically on maternal and child services, showed that there exists "moderate wealth-based disparities" due to underlying socioeconomic factors such as employment status and educational attainment of parents, as well as the birth order of the child. Other factors noted were the religion of the mother and perceived subjective distance from the residence of the mothers to the health facility providing maternal health services. This study highlighted the need to address poor education, as one of the demographic determinants of health, as well as the importance of implementing equitable health programs focused on underserved areas in the country. ${ }^{12}$

Based on 2016 figures, the Philippines has 1,224 hospitals, 2,587 city/rural health centers and 20,216 village health stations. Examining hospital bed distribution, twothirds of the beds were located in Luzon, including the National Capital Region (NCR). NCR specifically had an allocation of 23.1 beds to 10,000 population while only less than 10 beds in the rest of Luzon, in Visayas, and in Mindanao. ${ }^{10}$ In a study by Sablan (2018), health facilities in the Philippines were able to deliver basic services that pertain to survival functions. ${ }^{25}$ These include essential newborn care, breastfeeding and complementary feeding, integrated management of childhood illnesses (diarrhea, respiratory infections and fever), and accurately measuring weight and height. However, the health facilities showed a lag in the "thrive" activities and programs such as: (1) inability to obtain $z$-scores of the anthropometric measures taken or a nutritional assessment; (2) frequent unavailability of Ready-to-Use Therapeutic Food (RUTF) and Ready-toUse Supplementary Food (RUSF) for patients considered to be stunted and malnourished, and frequent stock-outs of health promotive and/ or curative agents (e.g. vaccines and medications); and (3) a 50\% correlation of the assessment of signs and symptoms identified in Integrated Management Childhood Illness (IMCI) guidelines between the health workers and the assessor. ${ }^{25}$ Another study on service utilization patterns for under five children with diarrhea and/ or respiratory illness showed that determinants of healthseeking behavior were maternal education and number of illnesses; while household size and economic status, affected decision on whether to choose public or private provider. ${ }^{26}$

Moving towards the supply-side of service delivery, primary care has been battling with patient satisfaction of human resource for health (HRH) as it is generally perceived 
by the public as inefficient and a source of low- quality health care service. ${ }^{27}$ According to the Professional Regulation Commission in 2016, "the 5-year annual production of new health professionals includes 2,700 physicians, 2,500 midwives, 4,100 medical technologists, and 600 dentists." 28 In 2017 , more than $50 \%$ of the nurses, midwives, and medical technologies were engaged in the public sector. ${ }^{10}$ However, maldistribution of HRH further contributes to the gap in service provision in underserved areas. For example, in 2017, the Autonomous Region of Muslim Mindanao had a density of 4.2 nurses , 2.6 midwives, 0.9 doctors and 0.3 medical technologists per 10,000 population compared to the National Capital Region which has a density of 12.6, 3.3, 10.6 and 3.2, respectively. ${ }^{10}$ Migration of health professionals inherently led to HRH shortage that worsened the health status of the poor and underserved areas, contributing to inequity. Externalities were identified which include geographic and technical maldistribution (prevalence of more specialists than generalists/ primary care providers). ${ }^{29}$ ThePhilippine Health Agenda for 2016 to 2022 noted that public facilities in the Philippines have less than 20\% medical practitioners that are actively caring for around $70 \%$ of the health care needs of the population. ${ }^{3}$ In 2015, DOH reported that " 398 physicians (Doctors to the Barrios), 13,500 NDP nurses, 2,700 Midwives, 480 Dentists, and 1,120 Medical Technologists" were deployed to different public health offices and other facilities. ${ }^{3}$ However, it is reported that orientation and training, capacities possessed and expected functions in the areas of assignments of these health professionals are not clear. ${ }^{3}$ In 2017, DOH deployed to priority areas 516 doctors, 17,538 nurses and 4,549 midwives. ${ }^{28}$ Since majority of the Filipino population, particularly the poor, seek care from public health facilities, the ratio of health worker was reported to be less than 1 physician, 1 nurse, 2 midwives per 10,000 population..$^{28}$ This ratio is only $1 / 10^{\text {th }}$ of the WHO recommended 24/10,000 needed to attain the Millennium Development Goals for the health of the mother and the child. ${ }^{3}$ Also, existing HRH maldistribution voids the fact of having almost adequate number of $\mathrm{HRH}$ in the country, since it is insufficient in catering to the needs of the sub-population..$^{29}$ These inequalities in the utilization of $\mathrm{HRH}$ can be attributed to "lack of a functioning system of rationalizing" retention, development, recruitment, and training of health professionals." ${ }^{\text {"30 }}$

Furthermore, HRH retention especially in GIDA and armed conflict areas continue to be a problem. This was attributed mainly to low compensation, limited job opportunities, and poor working conditions. ${ }^{28}$ Another factor is the increasing international demand for Filipino health professionals, making emigration to developed countries more attractive, further contributing to shortage in local supply. ${ }^{31}$ Some of the recognized attributes of Filipino health professionals in the global community are their patience and compassionate care. Each year around 19,000 Filipino nurses leave the country to work in foreign lands. ${ }^{32}$ As cited in the handbook on return service obligation program of University of the Philippines College of Medicine, sixty -eight percent of Filipino doctors were reported to be working internationally in the mid-seventies and if the increasing trend continues, by 2030, the Philippines would be experiencing a deficit of 7.401 doctors. $^{33}$

In terms of the administrative aspect, it was noted in a study by Sablan (2018) that a basic medical set up (i.e. health staff, clean medical equipment, structured provision of services, availability of medical commodities, and comfortable room space) to provide health care services can be seen in the health facilities visited in the Philippines. ${ }^{25}$ However, there is a need to improve the provision of adequate supply of clean water and sanitation. The availability of toilets for persons with disabilities and females also needs to be improved. The lack of supply stocks was frequently experienced and seen by the health workers as one of the important reasons for being unable to provide health care services in the health facilities in the country. ${ }^{25}$ Lastly, due to the fast turnover of health professionals, such as nurses and other health workers, provision for continuous training on particular health programs is needed. ${ }^{25}$

\section{Initiatives in Addressing Inequities in Primary Care in the Philippines}

In attaining universal health care, health care components such as (i) primary care and essential public health functions, (ii) multisectoral policy and action, and (iii) empowered communities, must be progressive in action to insulate the population from financial risk and inequities. ${ }^{34}$ In order to address inequities, the WHO Committee on Social Determinants of Health (2008) recommended three principles of action, namely: (1) improve people's condition pertaining to which they were born, live, work, and grow old; (2) deal with the unequal distribution of money, resources, and power; (3) evaluate the existing problems and potential actions along with coming up with a workforce who will focus on the social determinants of health. ${ }^{27}$ In 2018, UNICEF and WHO collaborated to update the Alma Ata declaration on primary health care, where primary health care was identified as the key to achieve "Health for All." 34,35,36

There are different proposed models in prioritizing primary care and public health functions as well as governance and policy frameworks to attain and to sustain UHC and health-related SDGs. ${ }^{34}$ Five strategies were identified to integrate public health to primary health care: (1) targeting most disadvantaged areas for health resources and actions for improvement; (2) working for a full range of services that are essential for the initial contact with the health system; (3) providing early interventions; (4) delivering proactive care that promotes health and prevents illnesses through capacity building in primary care level; (5) and looking at a broader perspective so that the health care given to each person is seen in the context of outcomes of a population. ${ }^{34}$ These strategies served as the backbone to formulate the six models given as: 
(1) integration of public health professionals into primary care; (2) coordination of public health and primary care providers; (3) formulation of "comprehensive and proactive health packages that include public health;" (4) provision of primary care services within public health settings; (5) creation of public health incentives in primary care; and (6) provision of multidisciplinary public health training to primary care staff. ${ }^{2}$

With the identified contributors of inequities in health services, initiatives of various stakeholders to mitigate problems in health programs, facilities, human health resources, finances, and training in health care and management in primary care in the Philippines were detailed below.

\section{A. Health Programs}

\section{Preventive and Curative}

Before the adoption of the primary health care approach by the Philippine government, this strategy has already been implemented locally by faith-based organizations through their community-based health programs. After the enactment of the 1987 Constitution, cooperation with civil society flourished, as there is now a legal basis to synergize the efforts of both the government and non-government sectors. ${ }^{37}$

One of the NGOs involved was Health Futures Foundation, Inc. (HFI), with the aim to achieve equitable access to healthcare by providing health and development programs to marginalized communities. ${ }^{38}$ In their project, the ALAGA KA or ALAy sa Ginbawa At KAlusugan Program, HFI collaborated with the local government and private sector to build barangay health stations in rural communities. ${ }^{38}$ This project was piloted in Batangas in 2011, with the objective of increasing access to primary care for low-income families. By 2017, the project generated 12 health stations that were turned over to the communities, nine of which had birthing facilities. The project also established community and wellness programs which included formation of wellness clusters as well as training and capacity-building of wellness leaders. ${ }^{38}$

The Institute of Primary Health Care (IPHC) of the Davao Medical School Foundation formed the Katiwala Program or Kauna-unahang Katiwala ng Kalusugan in 1978 that aimed to train health workers as providers of simple preventive and curative healthcare services in a charity clinic. ${ }^{39}$ The program was later managed by the Development of People's Foundation (DPF) two years later as IHPC partnered with $\mathrm{DOH}$ in the rural areas of Davao. Through the Katiwala Program, IPHC was able to train about 1,200 health workers and at the same time, provided alternative health financing solutions, community health organization, and primary care services. ${ }^{39}$

With a broader area of coverage, Participatory Research Organization of Communities and Education Towards Struggle for Self-Reliance, otherwise known as PROCESS
LUZON, addressed health service inequity through medical and dental outreach to rural areas of Luzon. ${ }^{40}$ In Panay, PROCESS provided maternal and child health services to the community. ${ }^{40}$

In response to the high mortality due to Typhoon Haiyan (Yolanda) in Eastern Visayas, the Japan International Corporation Agency (JICA) initiated a program to augment the gaps in increasing the likelihood of maternal survival. ${ }^{41}$ These programs included Maternal and Child Project SIKAT (Strengthening, Integration, Knowledgeable, Accessible, Teamwork) 2006-2010 and Strengthening Maternal and Child Service in Eastern Visayas 2010-2016. ${ }^{41}$ Also, health staff from these regions attended a series of trainings in Japan that discussed "maternal and child health $(\mathrm{MCH})$ practices and policy implementation, and public-private partnership to promote rural health and health planning." ${ }^{41}$ Participants imbibed the importance of evidence-based health planning to properly earmark resources, well-defined roles in the health system, and strong health referral system. ${ }^{41}$

At the other end of the spectrum, private organizations addressed inequity through Corporate Social Responsibilities (CSR) which is defined by the World Bank as "the commitment of business to behave ethically and to contribute to sustainable economic development by working with all relevant stakeholders to improve their lives in ways that are good for business, the sustainable development agenda, and society at large." 42 The Corporate Social Responsibility Bill was filed in 2010 and approved in $2019 .{ }^{44}$ The Bill mandates all business organizations to take responsibility for their activities' impact on the communities and environment by looking at the interest of society. ${ }^{42,43}$ Health development along with other various activities such as relief and assistance during disasters, promotion of culture and education, comprises the CSR-related activities. The Bill further mandates recognition and giving of rewards to all organizations with CSR activities that are outstanding, innovative, and world class by the Department of Trade and Industry. ${ }^{43}$ An example is a bank foundation that focuses on the needs of the underserved through the rehabilitation of Rural Health Units. ${ }^{44}$

\section{Rehabilitative and Palliative}

In terms of the palliative and rehabilitative aspects of care, The Ruth Foundation (TRF) provides free communitybased hospice and palliative care services to home-bound elderly, adults, and children with chronic and/or terminal illnesses. ${ }^{45}$ The team involves palliative specialists, volunteer doctors, nurses, pharmacists, physical therapists, volunteers, and staff. To increase accessibility, TRF provides home visits for patients referred by different government institutions and communities who are in need of palliative services in the areas of Laguna, Cavite, Parañaque, and Muntinlupa. ${ }^{45}$ TRF also serves as a platform for capacity-building among nurses and volunteers across the country, focusing on building competencies in palliative and hospice care services. ${ }^{45}$ 


\section{B. Facilities}

Increased financing, particularly through the Health Facility Enhancement Program in 2008, paved the way to infrastructure development to build and repair rural health units, birthing facilities, and barangay health stations, in the hope that the operations of these health facilities could be improved and sustained. Once improved, these health facilities would be eligible for accreditation by the National Health Insurance Program for its Primary Care Benefit package. ${ }^{28}$

The increasing inputs in financing laid down means to improve access to primary care through better access to medicines, vaccines and technology, human resources for health, and health infrastructure. With the goal to make healthcare more readily available, House Bill No. 951 was filed in 2019. The Bill proposed the creation of super health centers, designed to provide free basic services that may include laboratory, dental, birthing and ambulance services, in densely populated areas. ${ }^{46}$

\section{Human Health Resources/Manpower}

Primary health care in the Philippines has been formally adopted by the national government as a strategy in attaining better health outcomes. This paved the way to various initiatives that started with a top-down organizational change in the then Ministry of Health, formation of district health systems, with a focus on improving the primary care services at the frontline level. This included the training of barangay health workers in district health systems. With the enactment of the Local Government Code of 1991, the management of health facilities and human resources of health to the local government units, including the provision of primary care services, among others, were decentralized. ${ }^{47}$

Various government agencies such as the Department of Interior and Local Government (DILG), Department of Health, Philippine Health Insurance Corporation, and the Department of Social Welfare and Development (DSWD) developed a community health team project that mandated barangay health workers and community health volunteers to take care of the needs of a catchment of families, usually the indigent members of the Pantawid Pamilyang Pilipino Program (4Ps). For the $\mathrm{DOH}$, this was supplanted by the HI-5 strategy which deployed nurses and midwives to undertake this mandate. ${ }^{28}$ In 2015, Universal Health Care High Impact Five Strategy (UHC-Hi-5), a 15-month nationwide strategy plan, was implemented by $\mathrm{DOH}$ "to produce the greatest improvement in health outcomes in 43 priority provinces," that focused on the five critical UHC interventions specifically, service delivery network, infant care, child care, maternal health care, and HIV/AIDS. ${ }^{48,49}$ To strengthen the service delivery, $\mathrm{DOH}$ and regional offices were mandated to deploy nurses and midwives in barangays as they deemed necessary. ${ }^{48,49}$

With the challenges faced by the Department of Health from this system, various programs were sought to improve the capacity and capability on management of health systems. Increasing the capacity to deliver health care services, in general, at the municipal and barangay level entailed the deployment of health professionals, initially with the Doctors to the Barrios program, and later joined by other cadres of health human resources, such as nurses, dentists, midwives, medical technologists, and pharmacists, with positive inclinations toward underserved areas. Capacity building was instituted in programs in the Department of Health such as the Field Management Training Program, and the leadership and governance programs in collaboration with civil society organizations. ${ }^{37}$

As for the role of the academic sector to produce different cadres of quality health professionals, there have been curricula and scholarship programs that instill and reinforce service in underserved areas such as the curriculum that adopts "socially-accountable health professional education (SAHPE)" which focuses on commitment to public service. ${ }^{50}$ It practices preferential admission favoring internal recruitment and grants provision within the community. This approach is adopted by Ateneo de Zamboanga University School of Medicine in response to the challenge of recruiting and retaining quality medical workforce in the communities of Western Mindanao. ${ }^{50}$ Similar approach is used by the University of the Philippines Manila School of Health Sciences (UPM SHS) with the SHS Step-Ladder Curriculum designed to produce different cadres of health professionals depending on their chosen course path. ${ }^{51}$ Halili et al. (2017) reported that UPM SHS curriculum, compared to conventional medical schools, imbibes advantageous attributes to graduates of medical professions, since it develops stronger desire and positive attitude to serve in poor communities; hence, higher social and economic gains. ${ }^{50}$ Furthermore, graduates were reported to have stronger inclination to work in rural health units or become generalists or municipal health officers in the rural health units. ${ }^{50}$

To provide solution to the inequitable distribution of medical doctors in the Philippines, the University of the Philippines College of Medicine (UPCM) in 1985 implemented the Regionalization Program. This program involves a process wherein applicants from regions which lack doctors, would be accepted in the college after fulfilling certain requirements. In 2005, all medical students admitted under the Regionalization Program have been mandated to serve their region for the number of years equal to duration of their medical education. To address the inequities that continue to persist in the healthcare setting, students entering the College in 2009, became part of the Return Service Obligation Program. This program requires UPCM graduates to serve in any part of the Philippines as a public health or community medicine practitioner, primary care practitioner, researcher, teacher, clinical resident and/or a student of a Masters or Doctoral Degree Program. ${ }^{33}$ 


\section{Funds}

In the first year of the implementation of the UHC Act, it is projected that a total of 257 billion pesos is needed. ${ }^{52}$ Republic Act 10351, or commonly known as Sin Tax Law, apart from being a legal intervention to decrease cigarette smoking and alcohol-intake among Filipinos, is also a source of funds for the implementation of the UHC Act. ${ }^{53,54}$ In January 2020, RA 11467, an act increasing taxes on alcohol and electronic cigarettes was signed into law. The Department of Finance reported that adding taxes to such products would yield around 47.9 billion pesos which will be used to finance the UHC program for year 2021 and around 356.9 billion pesos for the next five years. ${ }^{55}$

International organizations are another source of funding in the country, such as the Asian Development Bank (ADB) which has initiating inter-agency projects. $\mathrm{ADB}$ directly supports government reforms such as the "Pantawid Pamilyang Pilipino Program (4Ps)", a Conditional Cash Transfer (CCT) program of the DSWD. The 4Ps aims to provide financial support to poor households and meet development goals as part of the conditionalities on health, nutrition, and education. Financial assistance of up to $\mathrm{PhP}$ 6,000 per month has been provided to eligible households provided that the following health conditions are met: "(i) pregnant women must get prenatal care starting from the first trimester and get postnatal care thereafter; (ii) childbirth is attended by a skilled/trained professional; (iii) parents/ guardians must attend family planning sessions/mother's class, parent effectiveness service, and other services; and (iv) children under 5 years old must get regular preventive health check-ups and vaccines. ${ }^{.52,56}$

\section{E. Health Training}

In 1981 to 1990, before PHC was offered on a widerscale, health workers underwent capacity building to interface with chief executives, non-government organizations, and the community to gather active partners in implementing and delivering health programs..$^{55,57} \mathrm{In}$ terms of leadership building, Zuellig Family Foundation (ZFF) initiated programs such as the Bridging Leadership and Fellowship Program and Health Leadership and Management Program which were conducted in collaboration with $\mathrm{DOH}$ regional and central offices. ${ }^{58}$ Through the Municipal and Leadership Governance Program in partnership with the University of Makati, mayors from different municipalities, who shared the same political will in "reducing infant and maternal mortality in most health-challenged and most-isolated areas," participated in the training as "Health Leaders for the Poor." ${ }^{158}$ Narratives from the local chief executives who underwent the training showed that the ZFF program helped them in governing their respective municipalities through leadership models that led to improved health outcomes. ${ }^{58}$ ZFF programs also enabled local chief executives to shift focus from provincial hospitals to investments and improvements of peripheral hospitals, most especially in underserved areas. ${ }^{58}$

\section{DISCUSSION}

With the rapid growth of economy and strong country capacity, significant investments and improvements in health were carried out in the country for the past years. ${ }^{18}$ However, not all improved health investment equates to achieving the target goal, and the investment has not fully reached the vulnerable population. Despite the various multi-sector interventions, current health outcomes show that more should be done, especially in underserved areas. A number of Filipinos had premature deaths due to illnesses that have interventions which are proven to be effective and cost-effective. The knowledge of Filipino patients to make informed health decisions still needs significant improvement. ${ }^{23}$

Investing in primary care is worth prioritizing for public health gains as this reduces preventable morbidity and mortality, and increases availability and accessibility of basic resources, facilities and provides valued health services which altogether reduces inequities or disparities in service delivery. The envisioned advantages of investments rationalize the need for adequate and sustainable funds appropriation securely designated to improve primary care, particularly focusing on hard to reach areas. The inequity in finances is a complex problem that requires a more sustainable source of funds in order to be fully addressed. Current laws such as RA 11462 and RA 11223 have already legitimized source of funds for health services; however, at the population level, security of income among Filipinos should also be addressed. ${ }^{12}$

The inequity in human health resources is being addressed by the academic sector by having a curriculum of instilling a sense of patriotism among its students and requiring them to serve in identified underserved areas in the country. Social accountability is the emphasized value and desired outcome from the students, being inculcated at the early phase of their medical career. If more universities will adopt this curriculum, the country will have sufficient health professionals who would be willing and ready to serve across all the regions in the Philippines. Currently, having return service agreement among health graduates aids in sustaining the workforce within the country. It is important to note that structured and critically planned systems on student selection, training approach, deployment, and retainment must be secured.

Moreover, the considerations on promoting equity in health and development of Spencer et al. (2019) can be adopted in general, for the health system design. The strategies include strengthening individuals and communities, improving living and working conditions, and promoting healthy macro policies. ${ }^{21}$

Examining the demand side of service delivery should be noted, including the social determinants of health such as education, behavior, and household roles. ${ }^{12}$ Hence, analyzing the two sides of service delivery in understanding primary care is imperative. For Filipinos to practice to make informed 
decisions to seek care, all must be educated on where, when, and what health care services can be accessed, and to exercise their right to health. Stigmas, folk beliefs, and unconventional health practices should be rectified with sensitivity to culture and religion. With the anticipated strengthened $\mathrm{PHC}$ in $\mathrm{UHC}$, it is hoped that Filipinos would recognize the role of generalists, which could decompress the specialists. This would also increase utilization of primary care and promote proper referral system that will be put into place.

Initiatives of multi-sector stakeholders targeting different subpopulations and social accountability issues among the Filipinos, proved that achieving primary health care requires collective action towards addressing inequities. ${ }^{19}$ Community participation is essential in the development and sustainability of interventions specifically tailored to their contextualized needs. Different strategies will only translate to positive outputs if political will is guaranteed to propel and sustain the change in the system, reaching the poorest segments to effectively address health inequities. ${ }^{19,21}$

\section{RECOMMENDATIONS}

From the review of literature guided by the current gaps and challenges in primary care vis a vis multi-stakeholders initiative the following are recommended:

\section{For the Government}

1. Ensure sustainability of healthcare resources for guaranteed continuity of care through improved financing schemes and performance accountability of health workforce and program managers at all levels of the health system.

2. Strengthen health care promotion to improve healthseeking behavior and instill evidence-informed health decision making among Filipinos.

3. Address the underlying determinants of poor health care such as poverty, geographic isolation, and socio-cultural barriers.

4. Invest in physical infrastructure including those which secure source of clean water, nutrition, sanitation, and ventilation to attain efficient and effective provision of services.

5. Appropriate funds for continuous research for assessment and evaluation that will aid policymakers and implementers in making short- and long-term interventions.

For specific roles of government sector, the following are recommended:

\section{Department of Health}

1. Capacitate healthcare providers with technical and managerial competencies by providing regular training covering all aspects of care with the end goal of continuous improvement.
2. Have regular assessment of the quality of service visa-vis health outcomes in the country stratified through different factors of attaining quality health care, to determine the greatest contribution of inequities.

3. Improve primary care trust among the general population while providing quality care in the primary care setting.

\section{Local Government Units}

1. Advocate and consolidate efforts from different sectors of society, government, NGOs, academe, and others, to promote health equity.

2. Adopt a whole-of-government approach in linking agencies' functions and mandates. This could be institutionalized through the legislation of a strategic framework for action with CHED, PRC, and DOH, among others.

\section{Academe and Researchers}

1. Aid in capacitating health care providers with technical and managerial competencies with the end goal of continuous improvement.

2. Include social accountability in the curriculum as one of the outcomes among medical and allied health students. Provide opportunities for graduates to serve in underserved areas, with compensation at par to standards.

3. Research on and develop standards of primary care such as considering horizontal integration of services based on functional capacity of a unit. Define the needs of primary care through resource stratification, prioritizing the top conditions or those with the highest burden of disease. Then determine services, from assessment to management, from prevention to palliation, that can be provided at the primary care level.

\section{Statement of Authorship}

All authors participated in data collection and analysis, and approved the final version submitted.

\section{Author Disclosure}

All authors declare no conflicts of interest.

\section{Funding Source} HPSR

This project was funded by the DOST DOH AHEAD-

\section{REFERENCES}

1. The 1987 Philippine Constitution [Internet]. [cited 2019 Dec 28]. Available from: https://www.officialgazette.gov.ph/constitutions/1987constitution/

2. An Act Instituting Universal Health Care for All Filipinos, Prescribing Reforms in the Health Care System, Amending for The Purpose Certain Laws, Appropriating Funds Therefore and for Other Purposes. Republic of the Philippines, RA 11223. February 20,2019.

3. Cabral E. The Philippine health agenda for 2016 to 2022. Philipp J Intern Med. 2016 Apr-Jun; 54(2):1-11. 
4. Telehealth Act of 2012. House Bill No. 6336. 15th Cong., 2nd Sess. 2012

5. Philippine eHealth Systems and Services Act of 2017. Senate Bill No. 1618. 17th Cong., 2nd Sess. 2017.

6. World Health Organization. Primary Health Care [Internet]. 2019 [cited 2019 Sep 2]. Available from: https://www.who.int/news-room/ fact- sheets/detail/primary-health-care.

7. World Health Organization. DOH, WHO highlight need for primary health care in UHC: Joint DOH and WHO News Release [Internet]. 2019 Apr 8 [cited 2019 Sep 2]. Available from: https://www.who. int/philippines/news/detail/08-04-2019-doh-who-highlight-needfor-primary-health-care-in-uhc.

8. Bautista V. Challenges to sustaining Primary Health Care in the Philippines [Internet]. 2001 [cited 8 Mar 2020]. Available from: https://cids.up.edu.ph/wp-content/uploads/Challenges-toSustaining- Primary-Healthcare-in-the-Philippines-vol.5-no.2-JulyDec-2001-5.pdf.

9. Tomacruz S. Duque: access to primary health care depends on coordination with LGUs [Internet]. 2018 [cited 8 Mar 2020]. Available from: https://www.rappler.com/nation/207068-accessprimary- health-care-dependent-coordination-lgus.

10. Dayrit MM, Lagrada LP, Picazo OF, Pons MC, Villaverde MC. The Philippines Health System Review. Vol. 8 No. 2. New Delhi: World Health Organization, Regional Office for SouthEast Asia; 2018.

11. Philippine Statistics Authority (PSA) and ICF. Philippines National Demographic and Health Survey 2017. Quezon City, Philippines, and Rockville, Maryland, USA: PSA and ICF. 2018.

12. Hodge A, Firth S, Bermejo R, Zeck W, Jimenez-Soto E. Utilisation of health services and the poor: deconstructing wealth-based differences in facility-based delivery in the Philippines. BMC Public Health. 2016 Jul; 16:523. doi: 10.1186/s12889-016-3148-0.

13. Picazo O, Ulep VG, Ortiz DA, Aldeon M, dela Cruz NA. Explaining the large disparities in health in the Philippines. Makati City: Philippines Institute for Development Studies [Internet]. 2013 [cited 8 Mar 2020]. Available from: http://dirp4.pids.gov.ph/ris/pn/ pidspn1308.pdf.

14. ANACT AMENDING REPUBLIC ACT NO.7875,OTHERWISE KNOWN AS THE "NATIONAL HEALTH INSURANCE ACT OF 1995, RA 10606. June 19, 2013.

15. The FOURmula One (F1) Plus for Health Monitoring and Evaluation (M\&E) System. DOH A.O. 2019-0003. Apr 24, 2019.

16. Universal Health Care: Implementing Rules and Regulations [Internet]. [cited 2019 Dec]. Available from: https://www.doh.gov.ph/ sites/default/files/health_magazine/UHC-IRR-signed.pdf

17. Craig P. Health Inequalities Action Framework. Scotland: NHS Health Scotland; 2013.

18. Van Olmen J, Criel B, Bhojani U, Marchal B, van Belle S, Chenge MF, et al. The Health System Dynamics Framework: The introduction of an analytical model for health system analysis and its application to two case-studies. Health Culture and Society [Internet]. 2012 [cited 2019 Sep]. Available from: https://hcs.pitt.edu/ojs/index.PhP/hcs/article/ view/71/96.

19. World Health Organization, Commission on Social Determinants of Health. Closing the gap in a generation: Health equity through action on the social determinants of health. CSDH final report. Geneva: WHO; 2008.

20. Beattie A, Yates R, Noble D. Thematic Paper: Accelerating Progress towards Universal Health Coverage for Women and Children in South Asia, East Asia and the Pacific. Nepal: UNICEF Regional Office South Asia; 2016.

21. Spencer N, Raman S, O'Hare B, Tamburlini G. Addressing inequities in child health and development: towards social justice. BMJ Paediatr Open. 2019 Aug; 3(1):e000503. doi:10.1136/bmjpo-2019-000503.

22. Chopra M, Sharkey A, Dalmiya N, Anthony D, Binkin N. Strategies to improve health coverage and narrow the equity gap in child survival, health, and nutrition .Lancet. 2012 Oct; 380(9850):1331-40. doi: 10.1016/S0140-6736(12)61423-8.

23. Country cooperation strategy at a glance Philippines [Internet]. 2018 [cited 23 Jan 2020]. Available from: https://apps.who.int/iris/
bitstream/handle/10665/136828/ccsbrief_phl_en.pdf;jsessionid=EC8 1BD90780121F761306214127EABE3?sequence $=1$

24. Blas E, Gilson L, Kelly MP, Labonte R, Lapitan J, Muntaner C, et al. Addressing social determinants of health inequities: what can the state and civil society do? Lancet. 2008 Nov; 372(9650):1684-9. doi: 10.1016/S0140-6736(08)61693-1.

25. Sablan B. Implementation review of interventions for primary health care for newborns, infants and young children in the Philippines. 2018.

26. Thind A, Cruz A. Determinants of children's health services utilization in the Philippines. J Trop Pediatr. 2003 Oct; 49(5):269-73. doi: 10.1093/tropej/49.5.269.

27. De Mesa R, Galingana CL, Marfori JR, Rey M, Sundiang N, Celeste $\mathrm{J}$, et al. Impact of improved primary care on patient satisfaction: results of a pilot study in the University of the Philippines. Int J Health Plann Manage. 2019 Oct; 34(4):e1651-e1660. doi:10.1002/hpm.2862.

28. Panelo CIA, Solon OJC, Ramos RM, Herrin AN. The Challenge of Reaching The Poor with a Continuum of Care: A 25-year Assessment of Philippine Health Sector Performance. Quezon City; 2017.

29. Caballes A. An Appraisal of the Policy Environment for Philippine Hospital Sector Development. Manila. 2009. Unpublished.

30. World Health Organization. Human Resources for Health Country Profiles: Philippines. Manila: WHO Regional Office for the Western Pacific; 2013

31. Caballes A. Human Resources for Health and Philippine Policy Options. Acta Med Philipp. 2009; 43(3):49-57.

32. Almendral A. 10 million Filipinos endure hardship abroad as overseas workers [Internet]. 2018 [cited 2020 Jan 1]. Available from: https:// www.nationalgeographic.com/magazine/2018/12/filipino-workersreturn-from-overseas-philippines-celebrates/.

33. University of the Philippines Manila, College of Medicine. Handbook on the UPCM return service obligation program and the regionalization program [Internet]. 2017 [cited 2019 Sep]. Available from: http:// upcm.ph/wp-content/uploads/2018/07/Unified-handbook-RSOPand-RP-updated-for-AY-2017-2018-.pdf.

34. World Health Organization and United Nations International Children's Emergency Fund. Technical Series on Primary Health Care Primary health care: closing the gap between public health and primary care through integration. Europe: WHO Regional Office; 2018.

35. World Health Organization and United Nations International Children's Emergency Fund. A Vision for Primary Health Care in the 21st Century. Kazakhstan: WHO and UNICEF; 2018.

36. World Health Organization. WHO called to return to the Declaration of Alma-Ata [Internet]. 1978 [cited 2019 Sep 2]. Available from: https://www.who.int/social_determinants/tools/multimedia/alma_ ata/en/.

37. Tiglao T. A century of public health in the Philippines. Taguig, Philippines: National Academy of Science and Technology; 1997.

38. Healthfuturesfoundation.com. Philippines: Barangay Health Stations [Internet]. 2019 [cited 2019 Sep 2]. Available from: https:// www.healthfuturesfoundation.com/our-work/programs/alagaka\#descriptions.

39. Bastian J. Health Promoters Making Progress in the quest for Better Health Care System and Policies. Japan: Asian Health Institute [Internet]. 2014 [cited 2019 Sep]. Available from: http://ahi- japan. sakura.ne.jp/english/html/common/fckeditor/editor/filemanager/ connectors/PhP/transfer.PhP?file=/uid000002_456E676C697368204 E4C2339352831292E504446

40. Process Panay Foundation Inc. [Internet]. [cited 2020 Jan]. Available from: https://processfoundationpanay.weebly.com/

41. Jica.go.ph. Training programs in Japan support maternal health and child welfare efforts in Eastern Visayas [Internet]. 2019 [cited 2019 Sep 16]. Available from: https://www.jica.go.jp/philippine/english/ office/topics/news/190301.html

42. An act institutionalizing corporate social responsibility providing incentives therefore, and for other purposes. Republic of the Philippines. SB 1239 [Internet]. [cited 2020 Jan 9]. Available from: https://www. senate.gov.ph/lis/bill_res.aspx?congress=15\&q=SBN-1239.

43. Republic of the Philippines. House of representatives. Corporate social responsibility bill approved [Internet] 2019 [cited 2020 Jan 
30]. Available from: http://congress.gov.ph/press/details.PhP? pressid $=11291$

44. bdo.com.ph. BDO Unibank's Corporate Social Responsibility [Internet]. 2012 [cited 2019 Sep 3]. Available from: https://www. bdo.com.ph/corporate-governance/corporate-social-responsibility

45. ruth.ph . The Ruth Foundation for Palliative and Hospice Care [Internet]. 2019 [cited 2019 Sep 7]. Available from: https://www.ruth. $\mathrm{ph} /$ what-we-do

46. An Act Providing the creation of super health centers in every City or Municipality and other densely populated areas. House Bill no. 951. 18th Cong., 1st Sess. 2019.

47. Khor M, Lin L. Good Practices and Innovative Experiences in the South: Citizen Initiatives in Social Services, Popular Education and Human Rights. New York, United States of America: United Nations Development Programme; 2001.

48. DOH-CHD:Bicol. Universal Health Care i-5 Strategy [Internet]. [cited $2020 \mathrm{Jan}$ ]. Available from: http://ro5.doh.gov.ph/index.PhP/ universal-health-care-hi5

49. DOH. The DOH Files Towards Quality Healthcare for all [Internet]. Vol. 1. Issue 12 April 2015 [cited 2020 Jan]. Available from: https:// www.doh.gov.ph/sites/default/files/health_magazine/DOHApril. compressed.pdf

50. Halili S, Cristobal F, Woolley T, Ross SJ, Reeve C, Neusy AJ. Addressing health workforce inequities in the Mindanao regions of the Philippines: Tracer study of graduates from a sociallyaccountable, community engaged medical school and graduates from a conventional medical school. Med Teach. 2017 Aug; 39(8):859-65. doi: 10.1080/0142159X.2017.1331035.
51. Shs.upm.edu.ph. Academics: The SHS Step-Ladder Curriculum [Internet]. 2016 [cited 2019 Sep 2]. Available from: http://shs.upm. edu.ph/academics.

52. Asian Development Bank. Civil Society: An Overview. Mandaluyong: Philippines Country Office; 2013

53. Department of Health. Increasing sin taxes will save lives [Internet]. [cited 2020 Jan]. Available from: https://www.doh.gov.ph/ node $/ 16806$

54. An act restructuring the excise tax on alcohol and tobacco products by amending sections 141,142,143,144, 145, 8, 131 and 288 of Republic Act no. 8424. Republic Act No. 10351 [Internet]. 2012 [cited 2020 Jan 23]. Available from: https://www.officialgazette.gov. $\mathrm{ph} / 2012 / 12 / 19 /$ republic-act-no-10351/.

55. Gita-Carlos RA. Duterte signs law imposing higher taxes on alcohol, e-cigarettes [Internet]. 2020 [cited 2020 Jan 23]. Available from: https://www.pna.gov.ph/articles/1091709.

56. Son H, Florentino J. Ex-ante Impact Evaluation of Conditional Cash Transfer Program on School Attendance and Poverty: The Case of the Philippines no. 142. Mandaluyong: Asian Development Bank; 2008.

57. Bautista V. Challenges to sustaining Primary Health Care in the Philippines [Internet]. 2001 [cited 2020 Mar 8]. Available from: https://cids.up.edu.ph/wp-content/uploads/Challenges-toSustaining-Primary-Healthcare-in-the-Philippines-vol.5-no.2-JulyDec-2001-5.pdf.

58. Zuellig Family Foundation. Reducing health system fragmentation through improved leadership and governance: Annual and Sustainability Report. Philippines: Forest Stewardship Council; 2017. 